\title{
Think Big!
}

Big Data - Massendaten, wie man früher hierzulande gesagt hätte - meint als Schlagwort mehr als das. Wird von Big Data gesprochen, geht es in der Regel um neuere Techniken, um mit sehr großen Datenmengen umzugehen.

In Zeiten von rasant anwachsenden Informationsmengen lassen sich solche Techniken in vielfältiger Weise nutzen. Besonders die Marketingexperten haben das Thema für sich entdeckt. Dass die meisten heute umfassende Informationen über sich und ihre Interessen in sozialen Netzwerken ablegen, kommt dieser Entwicklung entgegen. Aber im Zeitalter des Internets der Dinge liefern auch Gegenstände beziehungswei-

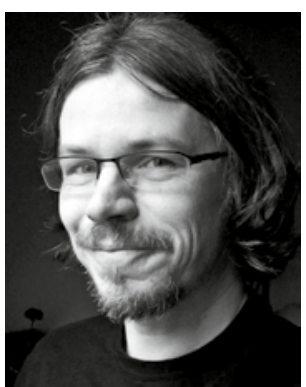

Peter Pagel

Chefredakteur se die Sensoren, mit denen sie versehen sind, Informationen. Big Data ist längst auch ein Thema für die Produktion.

Noch spannender ist aber, dass mit Big Data die Verknüpfung all dieser Daten möglich wird. Damit lassen sich Erkenntnisse über Menschen oder Unternehmen gewinnen, wie es in dieser Tiefe und in solchem Umfang nie zuvor denkbar war. Schon gar nicht in dieser Geschwindigkeit. Wir stehen bei der Nutzung von Big Data erst am Anfang. Ganz neue Geschäftsideen werden sich durch die geschickte Anwendung dieser Technik entwickeln - aber auch neue Herausforderungen etwa beim Datenschutz.

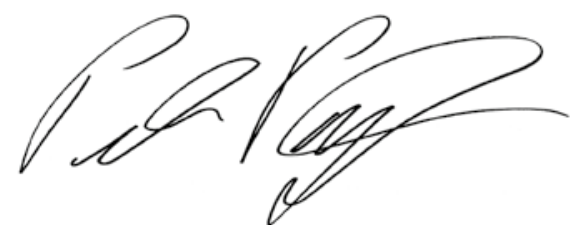

Peter Pagel 